EESTI NSV TEADUSTE AKADEEMIA TOIMETISED. 20. KOIDE

KEEMIA * GEOLOOGIA. 1971, NR. 2

ИЗВЕСТИЯ АКАДЕМИИ НАУК ЭСТОНСКОИ ССР. ТОМ 20
ХИМИЯ * ГЕОЛОГИЯ. 1971, N 2

\title{
ВЛИЯНИЕ КИСЛОРОДА НА КИНЕТИКУ ФОТОДЕГРАДАЦИИ 3,4-БЕНЗПИРЕНА
}

В предыдущих работах $\left[{ }^{1-4}\right]$ приводится характеристика кинетики фотохимического превращения 3,4-бензпирена, растворенного в различных органических жидкостях. под воздействием ультрафиолетового излучения в широком диапазоне длины волн от ближнего до дальнего ультрафиолета - при ограниченном доступе кислорода (воздуха) в систему, а также воздействие температурного фактора на нее. Роль кислорода в организации такого процесса необычна и сложна, ибо вместо тушения фотохимических реакций он принимает в некоторых из них непосредственное участие. Данные литературы [5] ограничиваются лишь частным случаем фотолиза 3,4-бензпирена в цнклогексане: насыщение раствора кислородом приводит к увеличению степени деградации канцерогена примерно в 4 раза по сравнению с превращением его в атмосфере азета.

Постановка соответствующего исследования в более общем плане с расширением нас́ора растворителей позволит наряду с выяснением фактической роли кислорода уточнить не вполне еще четкие предсгавления о механизме процесса, который, судя по нашим предыдущим работам $[3,4]$, отличается известной сложностью.

\section{Методика исследования}

В соответствии с поставленной задачей в исследовании предусмотрена постановка двух циклов опытов: опыты с насыщением раствора кислородом и эксперимент в атмосфере инертного газа - аргона. Каждый из них включает пять серий (по числу использованных растворителей: полярных ацетона, метанола и этанола $(96 \%)$ и неполярных углеводородов разной природы - бензола и $H$-октана). Источником излучения служит ртутно-кварцевая лампа сверхвысокого давления типа СВД-120-А. Для нее характерно сосредоточение основной части светового потока в области среднего ультрафиолета начиная с длины волн 200-210 нм и выше. Суммарная интенсивность облучения $\left(1,95 \cdot 10^{15} \kappa в а н т / \mu л \cdot c е \kappa\right)$ и начальная концентрация 3,4-бензпирена в растворе (на уровне близком к $2 \cdot 10^{-4} \mathrm{M}$ ) во всех экспериментах остаются неизменными.

Экспериментальная установка состоит из термостатированного реакционного сосуда - конической двугорлой колбы емкостью 100 мл (с центральной и боковой горловинами), снабженной магнитной мешалкой, и из системы дозировки и дополнительной очистки кислорода и аргона. Облучение образца производится через специальную кварцевую пробку в центральной горловине сосуда, снабженную в верхней части 
шліифованной горизонтальной кварцевой пластиной, проницаемой для всего светового потока. Лампа помецается над реакционным сосудом на строго заданном расстоянии и может быть отделена от него непрозрачным фильтром.

После помещения в реакционную колбу образца из последней вытесняется воздух путем достаточно длительной продувки кислородом или аргоном. В системе перед прекращением продувки устанавливается избыточное давление 80 мм вод. ст., контролируемое U-образным манометром. После пуска мешалки снимается непрозрачный фильтр с предварительно включенного излучателя и начинается отсчет времени.

В эксперименте использованы химически чистые реактивы: 3,4-бензпирен фирмы Fluka AG, Buchs SG и растворители (х. ч.), дополнительно очищенные и высушенные (за исключением этанола). Методика определения концентрации 3,4-бензпирена в растворе и продуктов его деградации описана в $\left[{ }^{1-3}\right]$. Следует указать, что не вполне строгое на первый взгляд использование $96 \%$-ного водного этанола в качестве одного из растворителей связано с получением сравнительных феноменологических данных для последующих биологических исследований.

\section{Результаты исследования и их обсуждение}

На рис. 1 приведены кинетические кривые, характеризующие накопление продуктов превращения 3,4-бензпирена (или убыль последнего в процессе деградации) для каждого из растворов в присутствии кисло-
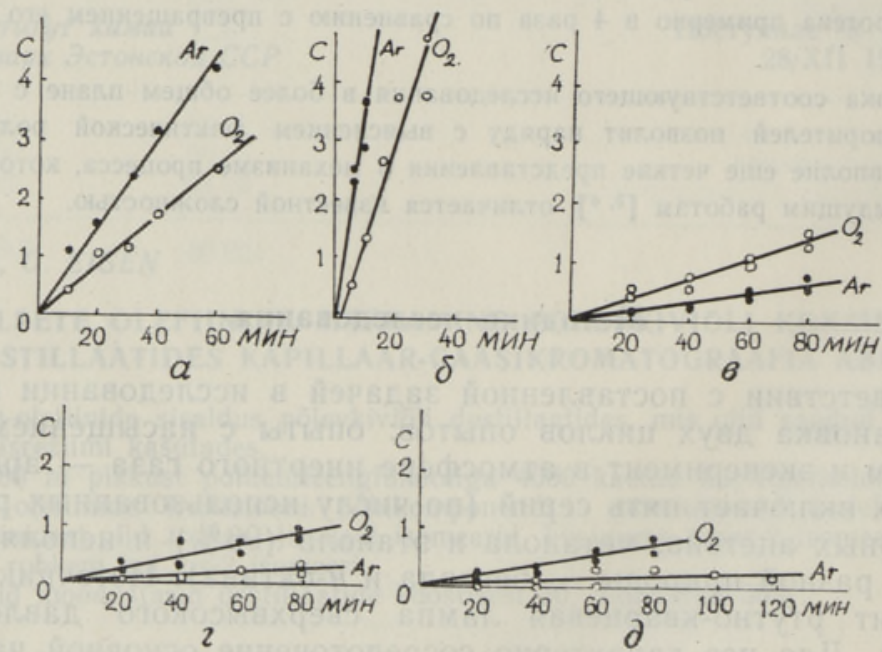

Рис. 1. Кинетика фотодеградации 3,4-бензпирена в метаноле $(a)$, ацетоне $(\sigma)$, бензоле $(в)$, октане $(2)$ и этаноле $(\partial)$ в присутствии кислорода и атмосфере аргона. На оси ординат концентрация продуктов деградации, г/мл.10-5; на оси абсцисс - длительность облучения, мин.

рода или в атмосфере аргона. Они показывают, что независимо от природы жидкой и газовой фаз суммарный процесс описывается макрокинетическим уравнением нулевого порядка. На этом основании вычислены значения констант скорости суммарной реакции, квантового выхода превращенного 3,4-бензпирена и молярной степени его превращения в. 
Макрокинетическая характеристика процесса фотодеградации 3,4-бензпирена в различных растворителях и в атмосфере кислорода или аргона

\begin{tabular}{|c|c|c|c|c|c|c|c|c|c|c|}
\hline \multirow{2}{*}{$\begin{array}{c}\text { Наименование } \\
\text { показателей }\end{array}$} & \multicolumn{2}{|c|}{ Ацетон } & \multicolumn{2}{|c|}{ Метанол } & \multicolumn{2}{|c|}{ Бензол } & \multicolumn{2}{|c|}{ н-Октан } & \multicolumn{2}{|c|}{ Этанол $96 \%$} \\
\hline & $\begin{array}{c}\text { Кис- } \\
\text { лород }\end{array}$ & Aprori & $\mid \begin{array}{c}\text { Кис- } \\
\text { лород }\end{array}$ & Aргон & $\left|\begin{array}{c}\text { Кис- } \\
\text { лород }\end{array}\right|$ & Аргон & $\begin{array}{c}\text { Кис- } \\
\text { лород }\end{array}$ & Aргон & $\begin{array}{c}\text { Кис- } \\
\text { лород }\end{array}$ & Aргон \\
\hline
\end{tabular}

Начальная концентрация 3,4-бензпирена

$\begin{array}{lllllllllll}\text { в растворе: } M \cdot 10^{-4} & 2,02 & 2,02 & 1,88 & 1,88 & 2,31 & 2,31 & 1,88 & 2,13 & 2,62 & 2,62 \\ \text { 2/ } \mathbf{\mu} \cdot 10^{-5} & 5,1 & 5,1 & 4,73 & 4,73 & 5,84 & 5,84 & 4,75 & 5,37 & 6,6 & 6,6\end{array}$

Постоянная скорости суммарной реакщии $(k)$, моль $/ \Omega \cdot u \cdot 10^{-5} 32$

Квантовый выход превращенного 3,4 -бензпирена (Ф), молек/квант $\cdot 10^{-4}$
Молярный циент превращения 3,4-бензпирена $\left(k^{\prime}\right)$, сек-1.10-4 $27,6 \quad 75$ $88,2 \quad 10,3$

0,3

(1)

,

единицу времени (условно названа нами константой деградации), которые приведены в прилагаемой таблице наряду со сведениями об исходной концентрации реагента.

Данные таблицы и рис. 1 убедительғо свидетельствуют о значительной роли природы растворителя в изучаемом процессе. Так, абсолютные величины всех кинетических показателей, безотносительно к составу газовой фазы, заметно убывают для ряда: ацетон $>$ метанол $>$ бензол $>$ $>$-октан $>$ этанол $(96 \%)$. В тесной связи с природой растворителя находится и характер воздействия кислорода, присутствие которого всистеме в одних случаях ускоряет, а в других - ослабляет фотодеградацию бензпирена. При этом в случаях фотолиза растворов в ацетоне и метаноле наличие кислорода обусловливает снижение скорости и уменьшение квантового выхода превращения 3,4-бензпирена. Для остальных же растворителей, напротив, характерно ускорение деградации канцерогена в присутствии кислорода.

Данные о составе реакционной смеси в известной мере позволяют объяснить природу этих явлений. В реакционной смеси при фотолизе растворов в ацетоне и метаноле в атмосфере аргона определены продукты реакций двух типов: ассоциации молекул 3,4-бензпирена с образованием так называемых простых полимеров (напр., плотносшитого димера, судя по УФ-спектрам - динафтокоронена) и взаимодействия растворенного вещества с активными (атомарными и радикальными) продуктами фоторазложения растворителей. $\mathrm{K}$ реакциям этого рода относятся: алкилирование по нанболее реакционноспособному пятому атому углерода в молекуле канцерогена (5-метил-3,4-бензпирен), гидрирование наиболее пассивных атомов углерода в пятом кольце $\left(1^{\prime}, 2^{\prime}, 3^{\prime}, 4^{\prime}\right.$-тетрагидро-3,4-бензпирен) и лишь при фотолизе в растворе метанола окисление за счет взаимодействия со свободным радикалом гидроксила (продуктом его разложения) до 5,8- и 5,10-дигидроксипроизводных 3,4-бензпирена и соответствующих дионов. Характерно, что карбонильный радикал (кислородсодержащий продукт фотолиза ацетона $\left.\left[{ }^{6}\right]\right)$ не вступает во взаимодействие с молекулами 3,4-бензпирена.

Присутствие кислорода - активного акцептора радикалов - способствует значительному сокращению выхода продуктов этих реакций, но не полному их исчезновению. В этом сказывается специфическая спо- 
собность канцерогенов к одновременному проявлению акцепторных и донорных свойств [3] и успешной конкуренции с кислородом за свободные радикалы и водород. Все же доминирующими компонентами реакционной смеси становятся продукты окисления бензпирена - соответ'ствующие гицроксипроизводные и хиноны, а также «сложные» полимеры, которые формируются на их основе в ходе дальнейших фотоокислительных превращений [3]. Это явление демонстрируется кривыми (рис. 2) изменения оптической плотности растворов в ацетоне и метаноле в полосе поглощения бензпиренхинонов (около 440 нм) как функции концентрации непрореагировавшего канцерогена в присутствии кислорода или аргона.

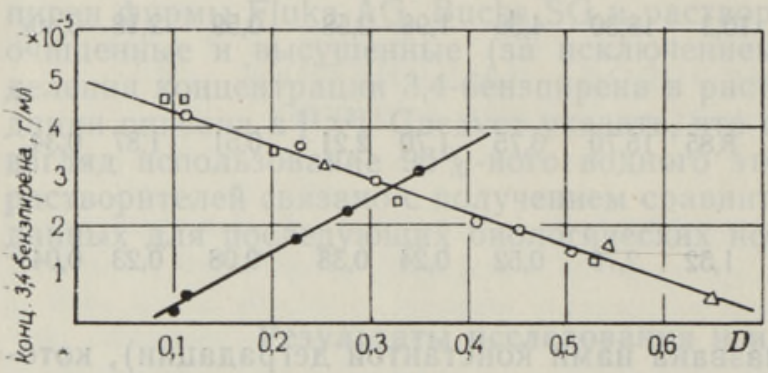

Рис. 2. Интенсивность поглощения $(D)$ в области -440 нм как функция снижения концентрации 3,4-бензпирена в процессе фотодеградации.

O - в ацетоне с $\mathrm{O}_{2} ;-$ - в ацетоне с $\mathrm{Ar} ; \square-$ в метаноле с $\mathrm{O}_{2} ; \triangle-$ в метаноле с $\mathrm{Ar}$.
Поскольку скорость реакции окисления 3,4 бензпирена, очевидно, меньше, чем взаимодействия его молекул с активными продуктами фотолиза ацетона или метанола (есть основания полагать, что для обонх растворов она примерно одинакова), то все кинетические показатели суммарного процесса в атмосфере аргона по абсолютной величине существенно выше, чем в присутствии кислорода. Различие (примерно пятикратное) абсолютных значений скорости, степени превращения и квантового выхода деградации бензпирена при фотолизе в указанных растворителях в атмосфере аргона в пользу ацетона обусловлено, очевидно, тем, что область поглощения ацетона соответствует волновому диапазону падающего светового потока $(260$ нм), а для метанола она выходит за его пределы (около $190 \mathrm{~ms}$ ). В связи с этим фотохимическое превращение ацетона происходит непосредственно под воздействием фотонов на его молекулы и отличается относительной несложностью механизма и повышенной результативностью.

Интересный факт разложения метанола в этих условиях свидетельствует о своеобразном и усложненном механизме переноса энергии в системе 3,4-бензпирен - метанол. Переход молекулы канцерогена в результате атаки фотоном (область поглощения 220-400 нм) в синглетное или триплетное состояние - условие, очевидно, необходимое, но недостаточное для химического взаимодействия его со средой. Для этого обязательным, по-видимому, являегся: передача энергии от активированного растворенного вещества к растворителю; сенсибилизируемое 3,4-бензпиреном разложение последнего; выделение активных продуктов этого разложения и, возможно, дополнительная активация молекулы бензпирена вторым фотоном (так наз. двухфотонный механизм).

Справедливость этого предположения хотя и нуждается в специальной проверке в физияческом эксперименте, все же находит косвенное подтверждение и на материалах насгоящего исследования, которые относятся к фотодеградации 3,4-бензпирена в других растворителях в аналогичной ситуации.

Так, в частности, скорость фотопревращения 3,4-бензпирена в -н-октане (см. таблицу и рис.1) при отсутствии кислорода весьма мала. 
равно как и показатель по квантовому выходу деградации. Это объясняется не только тем, что область поглощения октана (около $190 \mathrm{mM}$ ), как и метанола, не соответствует волновому диапазону применяемого излучения. Дело еще и в том, что продуктами фоторазложения октана являются, как известно, молекулярный водород и радикальные осколки разных размеров с двумя свободными углеродными связями (в настоящих условиях в итоге вторичных реакций на их основе формируется некоторое количество полимерных сәединений), которые с молекулой бензпирена не могут реагировать. Превращения канцерогена при отсутствии кислорода, сводятся, по-видимому, к соударению активированных молекул его с образованием «простых» полимеров и малоэффективному переносу энергии от атакованного фотонами 3,4-бензпирена $\mathrm{k}$ растворителю.

В присутствии кислорода, как это видно из результатов эксперимента, деградация канцерогена заметно интенсифицируется (в четыре-пять раз), энергетическая эффективность ее также повышается (см. таблицу). В свою очередь, по данным нашей работы [2], 3,4-бензпирен оказывает чувствительное сенсибилизирующее действие на процесс окисления октана. Механизм такого процесса, по-видимому, в какой-то мере соответствует известной схеме сенсибилизации фотоокислительньх реакций:

$\mathrm{S}$ (сенсибилизатор) $\stackrel{h v}{\longrightarrow} \cdot \mathrm{S} \cdot$ (1) Инициирование
$\mathrm{S}^{\mathrm{*}}+\mathrm{RH}$
(2) То же

$\mathrm{R}^{\prime}+\mathrm{O}_{2} \longrightarrow \mathrm{RO}_{2}$

(3) Продолжение цепи

$\mathrm{RO}_{2}+\mathrm{RH} \longrightarrow \mathrm{ROOH}$ (молекулярный продукт) $+\mathrm{R}^{\cdot}(4)$ То же
$\mathrm{RC}_{2}+\mathrm{SH}^{-} \longrightarrow \mathrm{ROOH}$ (молекулярный продукт) $+\mathrm{S}(5)$ Обрыв цепи

Таким образом, в данной системе молекулы 3,4-бензпирена одновременно играют роль передатчика энергии непосредственно необлучаемым молекулам растворителя, сенсибилизатора и инициатора процесса окисления октана. Вследствие низкой концентрации его в растворе этот процесс не может протекать по цепному механизму, а квантовый выход его (учитывая также непрямое воздействие облучения на октан) сравнительно невелик. Естественно, обрыв цепи может произойти не только по этой причине или в итоге реакции по уравнению (5), но и вследствие взаимодействия между собой пар перекисных или октильных радикалов.

Механизм же фотоокисления и других превращений 3,4-бензпирена, который нас в особенности интересует, остается не вполне ясным. Возможным представляется взаимодействие соответствующего радикала или иона с молекулярным кислородом или, что кажется нам более вероятным, продуктом его активации - атомарным кислородом или озоном.

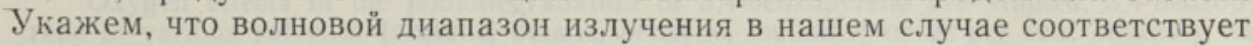
и области поглощения озона, что предохраняет его от разложения и создает предпосылки для поддержания постоянной концентрации активного окислителя в системе. Необходимо добавить также, что причиной относительно невысокой эффективности фотопревращения бензпирена в данной системе может быть активное вовлечение его молекул в процесс фотосенсибилизации окисления октана с возвращением их в исходное состояние при обрыве цепи по уравнению (5).

Аналогично рассмотренному случаю наличие в системе кислорода ускоряет фотодеградацию 3,4-бензпирена при использовании бензола в качестве растворителя, причем эффективность процесса в атмосфере 
аргона более высока, чем для системы бензпирен - октан. Механизм превращений, претерпеваемых растворителем при фотолизе в присутствии и отсутствии кислорода, пока не выяснен [6]. Известно лишь, что при фотолизе дегазированного бензола образуются некоторые весьма активные его изомеры. В настоящем эксперименте удалось установить формирование некоторого соединения ароматической природы, но неизвестного строения, которое, судя по УФ-спектру, не является ни фульвеном, ни дифенилом. Скорость накопления его в реакционной смеси не зависит от присутствия или отсутствия кислорода, как убедительно показывают спектры, снятые при разной экспозиции (рис. 3). Этот факт дает основание полагать, что дағное соединение является непосредственным продуктом облучения бензола, в формировании которого кислород не принимает участия. В продуктах же фотоокислительного воздействия на бензол нами ранее $\left[{ }^{1,2}\right.$ ] идентифицировано соединение с повышенным

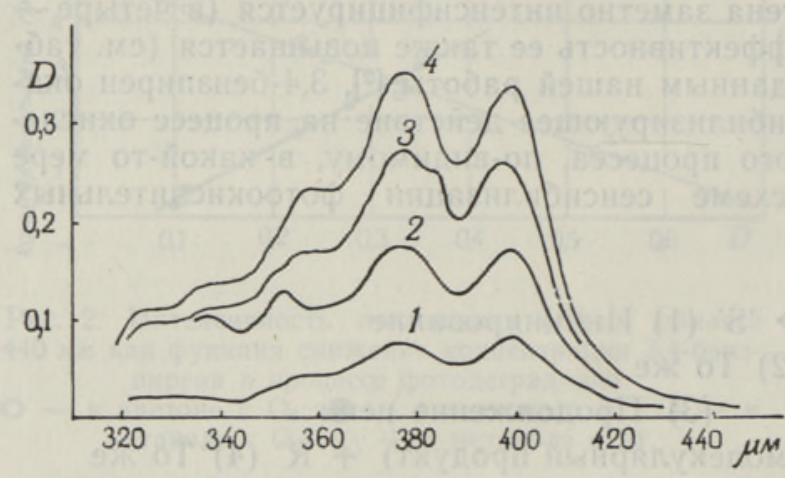

Рис. 3. Суммарные спектры поглощения облученного бензола в присутствии кислорода и в атмосфере аргона при различной длительности облучения (1 - 20 мин, 2 - 40 мин, 3 - 60 мин, 4-80мин).

молекулярным весом, спектр которого в ультрафиолете соответствует спектру поглощения дифенилантрацена - продукта полимеризации : поликонденсации бензола. Характеристика продуктов фотоокисления 3,4бензпирена в бензоле дана там же. Поскольку бензол сам по себе не может генерировать активный кислород в таком процессе, а окисление бензпирена является реальным фактом, остается полагать, что растворитель (возможно и растворенное вещество) также служит передатчиком поглощенной энергии кислороду и его активации, т. е. в конечном счете инициатором окисления бензпирена.

В заключение необходимо указать на аналогично выраженную тенденцию к повышению общей эффективности фотопревращения 3,4-бензпирена в присутствии кислорода в случае применения $96 \%$-ного этанола в качестве растворителя. В этой системе также отчетливо проявилосьсенсибилизирующее действие 3,4-бензпирена на фотоокисление растворителя. Относительно низкие кинетические показатели для этой системы по сравнению с данными для метанола, судя по данным литературы [6], объясняются наличием в этом растворителе воды и поглощением ею значительной части энергии излучения.

\section{Выводы}

Воздействие кислорода на фотодеградацию 3,4-бензпирена в значительной мере определяется природой растворителя и его поведением при УФ-облучении. По этим признакам исследованные системы можно условно распределить на две группы. Первая из них включает растворители (ацетон, метанол), легко расщепляемые в процессе фотолиза с образованием активных атомарных и радикальных продуктов, непосредственно и с большой скоростью реагирующих с растворенным веществом. Ввод кислорода, сильного акцептора радикалов, в такую систему сни- 
жает концентрацию этих реагентов и отрицательно сказывается на эффективности деградации бензпирена.

Ко второй группе относятся растворы канцерогена в органических жндкостях (бензол, октан), продукты УФ-облучения которых чрезвычайно ограничено или воэбще не реагируют с 3,4-бензпиреном. В таких системах кислород играет роль не акцептора радикалов, а основного реагента, и его присутствие повышает эффективность суммарного процесса фотодеградации канцерогена.

Участие 3,4-бензпирена в процессе окисления растворителя в качестве сенсибилизатора, по-видимому, также несколько снижает эффективность его фотопревращения. Механизм последнего, как показывает эксперимент, весьма сложен и нуждается в дальнейшем изучении.

\section{ЛИТЕРАТУРА}

1. Па альме Л., Г у берг и и М., Изв. АН ЭССР, Хим. Геол., 16, № 1, 32 (1967).

2. П а а ль м е Л., Г у б е р г и ц М., Изв. АН ЭССР, Хим. Геол., 17, № 2, 99 (1968).

3. П а а ль м е Л., Г у бе р г р ц М., Изв. АН ЭССР, Хим. Геол., 20, № 1, 31 (1971).

4. Па альм е Л., Г у бе ргр и іц М., Изв. АН ЭССР, Хим. Геол. (в печати).

5. Kuratsune M., Hiroh a t a T., Nat. Cancer Inst. Monogr., No. 9, 117 (1965).

6. К а лвер т Дж., Пи т с Дж., Фстохимия, М., 1968.

$\begin{array}{cc}\text { Институт химии } & \text { Поступила в редакцию } \\ \text { Академии наук Эстонской ССP } & 2 / \mathrm{VII} 1970\end{array}$

\section{LIA PAALME, M. GUBERGRITS}

\section{HAPNIKU MOJU 3,4-BENSOPUREENI FOTOKEEMILISELE LAGUNDAMISELE ERINEVATES LAHUSTAJATES}

3,4-bensopüreeni lahuseid atsetoonis, metanoolis, benseenis ja etanoolis $(96 \%)$ kiiritati kõrgsurve Hg-lambiga hapniku vōi inertgaasi (Ar) voolus. Olenevalt lahustajast mōjutab hapniku manulus tugevalt 3,4-bensopüreeni fotokeemilist muundumist. Hapniku manulusel vähenevad atsetooni ja metanooli lahuses lagunenud 3,4-bensopüreeni kvantsaagised, suurenevad aga benseeni, oktaani ja $96 \%$-lises etanooli lahuses lagunemisel.

\section{LIA PAALME, M. GUBERGRITS}

\section{INFLUENCE OF OXYGEN ON THE 3,4-BENZOPYRENE PHOTODEGRADATION IN VARIOUS SOLVENTS}

Oxygen effects in the photodegradation of 3,4-benzopyrene are studied. 3,4-benzopyrene in various solvents (acetone, octane, benzene, methanol or 96 per cent ethanol) was irradiated with a high pressure $\mathrm{Hg}$ lamp under inert gas ( $\mathrm{Ar}$ ) or oxygen atmosphere.

The presence or absence of oxygen depending on the nature of solvents strongly affects the photochemical degradation of 3,4-benzopyrene. The quantum yield of degradated 3,4benzopyrene will decrease in the presence of oxygen in acetone or methanol as soon as its value increases in octane, benzene or ethanol solutions. 